\title{
In Pursuit of Resistance: Pragmatic Recommendations for Doing Science within One's Means
}

\author{
Amy L. McLaughlin \\ Harriet L. Wilkes Honors College \\ Florida Atlantic University \\ amclaugh@fau.edu
}

\section{Introduction}

This paper investigates Charles Peirce's pragmatism, especially as it relates to questions of how we should conduct scientific inquiry. Peirce argues that the scientific method is the best method of inquiry, at least in part because it takes reality as its object. His system also suggests that conformity with reality is best pursued through maximal resistance, which makes the optimal path for inquiry the path of greatest resistance. Limited resources mean that we cannot always pursue researches optimally, however. As a working scientist, Peirce was well aware of such limitations and recognized that economy in research involves some analysis of what it will cost to gather evidence and how that balances against the likely benefits of that research activity. Pursuing research economically, then, requires that one have some guidelines for gathering evidence in a way that will maximize production of knowledge. I argue that Peirce's own recommendations can be, and given his broader commitments should be, understood in terms of maximizing opposition.

\section{Inquiry According to Peirce}

For this discussion, two aspects of Peirce's account of inquiry are of particular importance. First is Peirce's insistence that inquiry always begins with a set of beliefs in hand. Second is that Peirce's model of inquiry relies fundamentally on the operation of 
doubt. In particular doubt is necessary for both prompting and sustaining inquiry. These aspects of Peirce's account are considered in some detail below.

According to Peirce, belief just is a habit of sorts; beliefs are manifest in us as propensities to act. In "The Fixation of Belief” he states, “Our beliefs guide our desires and shape our actions.... Belief does not make us act at once, but puts us into such a condition that we shall behave in some certain way, when the occasion arises” $(5.371-373) .{ }^{1}$ The propensity to act in a particular way under particular circumstances is indicative of habit.

The nature of the habit characteristic of belief is clarified in the passage below:

Belief is not a momentary mode of consciousness; it is a habit of mind essentially enduring for some time, and mostly (at least) unconscious; and like other habits, it is (until it meets with some surprise that begins its dissolution) perfectly self-satisfied. Doubt is of an altogether contrary genus. It is not a habit, but the privation of a habit. (5.417)

Beliefs, on Peirce's account, are dispositional not propositional, and the set of habits that constitutes one's belief system will continue unaltered unless and until it "meets with some surprise”. Once something happens to challenge one's belief set, one may be thrown into doubt. $^{2}$

Peirce concerned himself with what he termed 'genuine' doubt. He writes: “[T]he mere putting of a proposition into the interrogative form does not stimulate the mind to any struggle after belief. There must be a real and living doubt, and without this all discussion is idle” (5.376). To say that one recognizes a proposition to be dubitable is not the same as to doubt the proposition. Manufactured doubt, or doubt that is simply a matter of entertaining alternatives, Peirce thought useful for examining consequences and such, but it is not the sort of impetus to inquiry as is genuine doubt. He states "doubt has a limen,

\footnotetext{
1 References of this form (n.m), are to volume $n$ and paragraph $m$ of Peirce's Collected Papers.

${ }^{2}$ This is to be explored more deeply in what follows, especially with respect to the precise sort of relationship that exists between belief and doubt.
} 
that is, is only called into being by a certain finite stimulus” (5.416). ${ }^{3}$ Typically Peirce speaks of such stimuli as surprising, or recalcitrant experiences. Once some surprising stimulus presents itself, it is then possible for one to be thrown into a state of doubt. This state is sufficiently uncomfortable as to promote action of some sort. So, in "The Fixation of Belief,” Peirce states: “The irritation of doubt causes a struggle to attain a state of belief. I shall term this struggle inquiry...” (5.374). He acknowledges, of course, that this use of the term 'inquiry' may be non-standard. 'Inquiry', in Peirce’s sense, applies more broadly than the word in its usual sense and is defined by reference to its goal.

According to Peirce, the sole object of inquiry is the settlement of belief. If one's beliefs are already settled — that is, if one's beliefs have not been unsettled by doubt-then inquiry will not begin. Doubt is the promoter of inquiry and only occurs with the presentation of some surprising stimulus. But, surprise just is a thwarting of expectations, and having expectations requires that one have some beliefs about what is to be expected. Thus, inquiry cannot begin from a state absent of belief. Potential inquirers always begin with some set of beliefs already in hand. ${ }^{4}$ Included in this set are beliefs about what will count as relevant evidence, whose accounts are to be believed, how to tell when a hypothesis has been confirmed or defeated, etc. Any of one's beliefs (or some combination of these) may be susceptible to doubt, but none is scrutinized until some positive reason for doing so has presented itself. On Peirce's view, doubt arises only where one encounters some stimulus that poses a challenge to one's set of beliefs. When one's belief system is

\footnotetext{
3 See also 5.374-5.

${ }^{4}$ This discussion leaves aside the question of from where beliefs come initially - though a thorough study of Peirce's evolutionary cosmology would go some way to illuminating Peirce's stance on this issue. For such a study, see (Kronz and McLaughlin 2002). Peirce himself took up this issue, though his treatment has not thoroughly satisfied his critics. See, for example, (Scheffler 1974, 66-67). It is enough for the present purposes that we incontrovertibly do have beliefs and that they may be consistently treated in the way that Peirce treats them. The issue of whether Peirce's account of belief origination could be made satisfactory is left for future exploration.
} 
challenged, this may be sufficiently irritating to motivate one to inquiry - the sole purpose of which is to remove the irritation of doubt by settling on some suitable, perhaps revised, set of beliefs.

Doubt's abatement occurs when satisfactory beliefs are established, that is when one’s belief set is settled. Peirce says, "Doubt ... stimulates us to inquiry until it [doubt] is destroyed” (5.373). Once doubt is destroyed, inquiry is bereft of its prompt and thus we are left in the comfort and stability of that habit of mind known as belief - that is, unless and until some further challenge initiates the process of inquiry anew.

For Peirce, the only aim of inquiry is to settle belief, and the path that inquiry takes is determined by the method that one uses to achieve this aim. The key question at this point is how to decide which methods to use. Under Peirce's system, the criterion for judging a method of inquiry must be how well the method is suited to the goal of inquiry. Misak notes that, since "[Peirce] holds that the aim of inquiry is settlement of belief, he is right to insist that he can appeal only to efficiency in that regard to judge methods of inquiry” (1991, 56-57). The following discussion of Peirce's theory of inquiry focuses on Misak's reformed Peircean account, which attempts to address a significant criticism of Peirce's explicit account. The criticism she raises deserves to be taken seriously, more seriously, I suggest, than even she herself takes it.

\section{Peirce on Methods of Inquiry}

Peirce's strategy in arguing against specious methods is to show that the possibility will always remain that beliefs acquired through these methods become subject to doubt. Methods of inquiry that fix belief according to something potentially unstable cannot, according to Peirce, succeed in the long run. Primarily, this is because of the possibility 
that inquirers will recognize the potential instability, and that recognition alone will suffice to give rise to doubt. ${ }^{5}$ The only method of inquiry that successfully safeguards against the emergence of doubt is the scientific method, according to Peirce. ${ }^{6}$ The scientific method has corrective mechanisms built-in - it is sensitive to empirical and practical considerations. This method will not succumb in the same degree to the vagaries of individual opinion; the reason for this is science's aim at external reality. The fundamental hypothesis of science, as Peirce construes it, is that "[t]here are Real things, whose characters are entirely independent of our opinions about them” (5.384). Thus, the beliefs settled by the scientific method are supposed to be determined (at least in part) "by some external permanency - by something upon which our thinking has no effect” (5.384). So, while the scientific method does not necessarily result in permanently fixed belief, that is, belief that would never be subject to doubt, it does include safeguards against the inevitability of doubt's resurgence. The very nature of the method results in beliefs that are least susceptible to future doubt.

It is critical for Peirce to have a clear and appropriate account of which methods of inquiry to use, since his account of truth relies heavily on his account of inquiry. According to Peirce, one would arrive at the truth about any particular matter if one were to inquire far enough into the matter. Thus the truth about a matter is whatever opinion would be the final opinion, resulting from inquiry carried sufficiently far. ${ }^{7}$ However, Peirce's fallibilism precludes his accepting that we can ever know for certain whether any

\footnotetext{
5 This is, of course, only a very cursory treatment of Peirce's arguments against specious methods of inquiry, which for present purposes suffices. Much has been written on this subject, and I refer the interested reader to other sources for more detailed treatments of Peirce's theory of inquiry; see (Hookway 2000), (Levi 1991), (Misak 1991), (Short 2000), (Skagestad 1981).

${ }^{6}$ In his "The Logic of 1873" Peirce refers to this method as "investigation" and "reasoning."

${ }^{7}$ See, for example, 2.693, 5.408, 8.43, more obliquely 4.62 and 7.336. The reasonableness of this account of truth is not discussed here; the account is mentioned only to showcase the role that inquiry plays in Peirce's system.
} 
particular belief is true or not. Truth, then, on his account, serves primarily as a regulative ideal; its primary function is to motivate inquiry. So, it is critical that we know which avenues of inquiry are legitimate and which to avoid.

\section{Misak’s Challenge}

Misak agrees with Peirce's assessment of the methods. That is, she agrees that the methods Peirce claims to be specious are so. Misak takes issue, though, with Peirce's arguments for this claim. She claims that the arguments rely on an empirical, psychological fact about inquirers - that they will be influenced by opinions other than their own. If it were possible to safeguard against all opposing influence, (via, e.g., a "belief-freezing" pill), then whatever the method, it would satisfy Peirce's requirements for permanently fixing belief. The fact that any such safeguards might be built into an obviously specious method seriously undermines Peirce's argument. We turn now to Misak's arguments to this effect.

The first vulnerability Misak detects in Peirce's arguments against the three specious methods is that the arguments are based on a supposed psychological fact about inquirers - that when we encounter beliefs that differ from our own we will be prompted to examine our beliefs and perhaps to doubt them. The presumption that one is likely to take seriously the claims of others is plausible "because inquirers are members of a community, they utilize the results of other members” (Misak 1991, 58). This interdependence is so widespread, in fact, that Peirce claims: “[O]ne man’s experience is nothing, if it stands alone. If he sees what others cannot, we call it hallucination" (5.402 n.2). ${ }^{8}$ According to Misak, though, this will not suffice since judgments about competence are made with

\footnotetext{
${ }^{8}$ See also 7.644.
} 
respect to background beliefs. These beliefs will determine the relevant members of the community to whom attention should be paid. If it is implicit in the background beliefs that people who do not share belief $\mathrm{X}$ should not be listened to, where $\mathrm{X}$ is a first principle for example, the a priori method might safeguard against the emergence of doubt perfectly well. Thus, there may be opinions that are (more or less) permanently settled that were derived from methods Peirce explicitly rejects. Misak also points out that what counts as competence in science is not particularly well resolved. The fact that there are controversies in science, and that scientists do not unanimously accept results shows that even the scientific method can be subject to differences of opinion. Misak, though, finds material enough in Peirce's works to muster an alternative, and she thinks better, argument against specious methods.

It seems, from what has been said so far, that Peirce's account is as follows: Whatever is true is what would be accepted at the end of all possible inquiry. Inquiry just is the process of settling belief. So, those methods of inquiry that best fix a hypothesis in one's mind are the methods that will be best for arriving at the truth. Misak attempts to refine somewhat this naïve notion of inquiry. She claims that inquiry is not intended to fix hypotheses or habits simply; its intended result is the fixation of a habit that satisfies the requirements for being genuine belief. A hypothesis or disposition is a genuine belief, according to Misak, when it is sensitive and responsive to evidence $(1991,59)$. Otherwise, it is some tenacious psychological state, but not a belief. Peirce's account of truth, as Misak construes it, requires not that inquiry make hypotheses doubt-resistant but that it fix genuine beliefs - which are hypotheses that were gathered in ways that respond to evidence and that are themselves sensitive to evidence. Misak concludes as follows: 
So, given that a belief, in order to be a belief, must be sensitive to evidence for and against it, the aim of inquiry, on Peirce's account, is to get beliefs which are not merely fixed, but which are fixed in such a way that they fit with and respond to the evidence. $(1991,60)$

This criterion for genuine belief, Misak claims, overcomes the shortcomings of Peirce's explicit arguments and provides an appropriate measure for evaluating methods of inquiry.

\section{Objection to Misak’s Account}

Misak’s analysis is weighted heavily on the notion of evidence. On her account, legitimate methods are the ones that produce genuine belief, and the criterion for genuine belief is that it be sensitive to evidence. Defining genuine belief in terms of sensitivity to evidence requires that one give some suitable characterization of what is to count as evidence. Such characterizations, however, are notoriously difficult; entire treatises have been written in attempt to suitably characterize what should count as evidence. ${ }^{9}$ Thus, Misak’s account is programmatic at best - without a precise account of what is to count as evidence, Misak’s refinement is of little use.

One might think that Misak could easily dismiss the charge that she gives insufficient attention to defining evidence. Although the definition of genuine belief does involve reference to evidence-sensitivity, there is (she might claim) nothing in particular that is required about evidence in order for something to be sensitive to it. She might argue, for instance, that whatever the actual inquirer would count as evidence will suffice; and the same criterion need not be applied among different inquirers (or even among different inquiries by the same inquirer). What is crucial is that the belief achieved at the end of the process is in fact sensitive to evidence of some sort. Furthermore, being

\footnotetext{
${ }^{9}$ See for example: (Achinstein 2001), (Glymour 1980), (Horwich 1982).
} 
sensitive to evidence does not require that a belief be actually revised in light of whatever evidence comes along. No precise criterion for telling which evidence to take seriously need apply in the context of conducting inquiry. Thus, Misak might argue, no characterization of what is to count as evidence is necessary for determining what methods of inquiry are legitimate.

On Misak's account, one decides whether a method is a legitimate method of inquiry by testing to see whether it produces genuine belief. Testing for production of genuine belief might be done in one of two possible ways. Either one tests the result of the inquiry (the hypothesis or disposition formed as a result of the inquiry) to determine whether it is sensitive to evidence, or one tests the method to see whether in its production of the hypothesis or disposition the method takes account of evidence. In each case, one must consider what appropriately counts as evidence in order to determine which methods of inquiry are legitimate. Appealing to evidence as determinant to any degree of a method's legitimacy requires reference to an independent evidence-criterion. Without such a criterion in hand, anything one is willing to count as evidence suffices and consequently any method can count as legitimate. That is, Misak's account succumbs to the same objection she levels against Peirce. Criteria of evidence, just as much as criteria of competence, are determined according to background beliefs. Thus, any method could be made legitimate by appeal to suitable evidence criteria. Bereft of an independent criterion for determining what should count as evidence, Misak's account does not clarify but rather seems to muddy the waters. 


\section{The "Open Path" Alternative}

There is a relatively straightforward way of understanding Peirce's view that will resolve which methods of inquiry are to be deemed legitimate and which are not. Peirce defines a method of inquiry as aimed at fixing or settling belief. Also, inquiry begins, on Peirce's account, at the onset of doubt—defined as the absence of a fixed belief—and ends when one's beliefs are fixed. So, whatever can successfully remove doubt will be termed, on Peirce's account, a method of inquiry. Removal of doubt, however, clearly does not suffice to legitimate a method of inquiry. Peirce repeatedly refers to what he calls a "maxim" never to be infringed. This maxim is: "Do not block the way of inquiry" (1.135). ${ }^{10}$ Following Peirce's dictum, I propose that we consider legitimate those methods of inquiry that are capable of removing doubt without blocking the path of further inquiry. Thus, every legitimate method of inquiry will have two components: it will (1) settle belief by removing doubt, and (2) leave open the path to future inquiry into the matter. Here is where an explicitly normative element enters into the Peircean account, requiring that one settle one's beliefs about the matter, but do so in a way that leaves open the path to future inquiry. All of the methods that we would want to reject as obviously specious can be shown to fail legitimacy on this account.

Any methods by which beliefs are fixed according to pre-existing opinions are, according to the criterion mentioned above, clearly illegitimate. That is, they cannot successfully remove doubt and leave open the possibility of future inquiry, since they expressly take some beliefs to be fixed and so explicitly treated as closed to inquiry. The method of science, broadly understood, succeeds because science is treated as "self-

\footnotetext{
10 See also 1.156, 1.170, 1.175, 6.273, 8.243.
} 
criticizing, self-controlling and self-controlled, and therefore open to incessant question” (7.77).

There is one method considered by Misak that passes Peirce's legitimacy test (according to her construal of it) but is clearly to be counted among the illegitimate. Misak considers the possibility of making a 'belief-freezing' pill - a pill that one could take to permanently fix all beliefs in one's mind. Strangely enough, the belief-freezing pill method (given Peirce's account) counts as a method of inquiry; it does in fact settle belief, and it does so permanently. If one's state of mind is frozen, the prospect of changing habits or dispositions is closed (it need not be believed to be closed, but it must be in fact closed). Thus, the belief-freezing pill perfectly satisfies the aim of fixing belief, and so counts as legitimate on Peirce’s explicit account. Misak points out, however, that the belief-freezing pill method fails her legitimacy criterion. If such a pill were administered, the resulting state of mind of the pill-taker would not be, strictly speaking, a state of belief (in Misak's sense). Reliance upon the notion of evidence, however, makes Misak's own account as vulnerable as the account she hopes to fortify. The "open-inquiry” criterion introduced here, however, gives the same result as Misak’s account without falling subject to the same pitfalls. This method fails legitimacy, on my account, because it forever closes off the possibility of future inquiry. Once the pill has been swallowed, no issues may ever arise as the subject of inquiry. Thus this method is specious for it fails to leave the path to inquiry open.

\section{The Path of Greatest Resistance}

Inquiry is instigated, on Peirce's view, only by doubt. So keeping the path of inquiry open requires keeping susceptible to doubt the field of one's belief set that is 
relevant to the inquiry. This does not require that one be in a state of constant doubt, but rather it requires vigilance in detecting and pursuing possible sources of doubt. Peirce's recurring suggestions that doubt is an "irritation" and that it is "unsettling" might incline one to seek its permanent removal. ${ }^{11}$ Peirce agrees that the removal of doubt is a worthy pursuit, but he is careful to be explicit about how this goal is to be pursued. His system is predicated on fallibilism, the view that nothing is entirely certain, but nevertheless he believes that progress is possible. Indeed progress is ensured by continual probing and inquiry.

The best method of inquiry is the scientific method, which is characterized by taking reality as its object. According to Peirce, the real is "that whose characters are independent of what anybody may think them to be" (5.405). One particularly novel element of Peirce's approach is that on his view the real is encountered in experience as opposition. He tells us that our conception of the real "is a conception which we must first have had when we discovered that there was an unreal, an illusion; that is, when we first corrected ourselves" (5.311) As Thomas Olshewsky puts it, "[t]he only sense in which we know [a dynamical object] is negatively: when our actions and experiences are not habituated to conform to its habits, we confront it in unanticipated surprise” $(1994,28)$. When we form a belief about some matter, we do so with an expectation that the belief will serve us well in the future. This means, at least, that we develop the belief with an eye toward avoiding surprises. As long as our expectations are not thwarted we expect that our beliefs are fully adequate. This conformity with expectations, however, is no guarantee that our beliefs perfectly conform with reality. Even though nothing prevents our knowing objects as they really are, "we can never be absolutely certain of [knowing outward things

\footnotetext{
${ }^{11}$ See 5.373-375, 5.394, 7.317.
} 
as they really are] in any special case” (5.311). Olshewsky summarizes this aspect of Peirce's system as follows: "Phenomenologically, reality must be understood as opposition, and phenomenologically is the only way that we can understand reality” (1994, 28-29). Reality is manifest as opposition since this is the way in which it is primarily encountered. This is not to say that we only encounter reality in this way. Of course we make our way in the world and this means that we do somehow plot a course with and through reality; but it is only when the course takes an unexpected turn that reality as independent (of our conceptions and expectations of it) makes itself known.

Inquiry properly conducted just is inquiry toward truth, toward conforming one’s conceptions to reality. Insofar as we pursue this in earnest, we seek ways of comparing hypotheses to reality (testing hypotheses) and assessing the results. ${ }^{12}$ Since we encounter reality primarily as opposition, comparing hypotheses to reality requires that we maximize opposition. ${ }^{13}$ The most fruitful testing, then, will come in the form of negative tests, where we deliberately seek out circumstances that would undermine the hypothesis. If the hypothesis stands up to this sort of scrutiny, then our confidence in its future success is substantially and legitimately boosted. The best way to ensure against the resurgence of doubt is to take care that in conducting inquiry we accommodate as far as possible those scenarios that could otherwise become obstacles and thus doubt-producing circumstances. Subject the hypothesis under scrutiny to the most rigorous of tests; if it passes these then the subsequent emergence of doubt-prompting circumstances becomes less likely. ${ }^{14}$ Thus

\footnotetext{
12 Peirce makes some recommendations for how hypothesis testing should proceed, based on considerations of economy. Peirce's work on the economy of research is explored below.

${ }^{13}$ For a nice discussion of this issue, see (Olshewsky 1994).

${ }^{14}$ Deborah Mayo agrees that the severity of the tests a hypothesis passes is indicative of the degree to which the hypothesis is to be believed. She also characterizes Peirce's view of induction in similar terms. For her characterization, see section 12.2 of (Mayo 1996).
} 
the optimal path for scientific inquiry is the path of greatest resistance - seeking out potential obstacles, facing and accommodating those that arise, thereby enriching and fortifying our conceptions about the world.

\section{Economy of Research}

In practice, we cannot pursue all obstacles. Actual scientific inquiry is constrained by limited resources. Peirce refers explicitly to limitations in "money, time, energy, and thought” (7.220). Of course there may be other costs to doing research, such as risks incurred to one's professional reputation by pursuit of an unpopular research program. All of these factors, physical, personal, and social, are weighed by scientists in determining how to conduct their research. Which hypotheses to pursue and how best to pursue them is dictated by considerations about economy, involving cost/benefit analysis. Peirce was well aware of the need to economize in scientific investigation, and of the need to develop appropriate standards by which economy might be achieved. He writes:

Research must contrive to do business at a profit; . . . it must produce more effective scientific energy than it expends. No doubt, it already does so. But it would do well to become conscious of its economical position and contrive ways of living upon it. (7.159)

Much has been written about Peirce's discussions of abduction and the extent to which appropriate guidelines can inform the process of hypothesis formulation. Kronz \& McLaughlin (2005) notes that Peirce's work can contribute usefully to our understanding of how to set research priorities in the evidence-gathering phase. There, Kronz and McLaughlin address at length some of Peirce's specific recommendations for how to economically conduct scientific research in order to yield the most valuable information. Their discussion focuses on formally articulating the "Peircean Test Condition" as a 
supplement to Achinstein's theory of evidence. In what follows, I summarize some of the findings in Kronz \& McLaughlin (2005), but put those findings to substantially different use. I argue that Peirce's specific recommendations can be understood in light of his general epistemology and its implication that optimizing inquiry requires maximizing opposition. In particular, I argue that Peirce's strongest recommendations for how to go about economically amassing evidence are best understood as instantiations of the general recommendation to follow the path of greatest resistance.

For the purposes of the following discussion, we can think of evidence gathering as involving two broad phases: narrowing the field of viable hypotheses, and determining which experimental results to test for. Peirce’s work offers useful guidelines for navigating each of these phases, which I discuss below. While these phases are treated separately, such treatment does not imply that the phases are either exclusive or sequential. Their separation here is conceptual, and serves only as a convenient device for discussion.

\section{Narrowing the Field of Hypotheses}

Nicholas Rescher has discussed Peirce's work on economy of research, and notes that Peirce gives priority, on economic grounds, to two sorts of hypotheses..$^{15}$ The simpler among available hypotheses, Peirce claims, as have many others, are more economical. Simple hypotheses are operationally cheaper, since they will involve fewer variables to accommodate in experimentation and are likely to have more obvious and easily calculable application. Peirce also gives priority to hypotheses with high generality relative to cost. The more general the hypothesis, as Karl Popper noted, the more it will imply. Rescher carefully points out that Peirce also recommends preference for generality, but that he

\footnotetext{
${ }^{15}$ See chapter 4 of (Rescher 1978).
} 
balances generality against the costs of investigating those implications $(1978,83)$. These general recommendations, however, can serve only as general guides. Simplicity is a notoriously difficult concept to explicate with any degree of rigor, and generality relative to cost is not particularly useful without measures of generality and cost as well as some method for weighing them against one another. Fortunately, Peirce has much more specific suggestions, which can be applied without the addition of a great deal of conceptual baggage.

Presumably, the strongest among available hypotheses are the ones that deserve scientists' initial attention. Peirce would agree, but as Rescher, and Kronz and McLaughlin note, Peirce does not consider the strength of a hypothesis to consist merely in its likelihood. ${ }^{16}$ Instead, the strength or 'urgency' of a hypothesis is measured in terms of the resources that scientists would be willing to commit to its examination (2.780). That Peirce conceives thusly of the strength of hypotheses helps to explain why he gives precedence to hypotheses whose examination involves "very little expense of any kind" (7.220). Hypotheses that can be tested very inexpensively will be among the strongest. Kronz and McLaughlin point out that Peirce assigns priority to cheaply tested hypotheses not only because refutable hypotheses might be eliminated, but also because hypotheses that are contrary to existing presuppositions might be supported $(2005,73)$. Here is the first point where the implications of Peirce's general theory of inquiry, that we should seek the path of greatest resistance, dovetail with his specific research recommendations. In suggesting that we begin not with those hypotheses that seem most likely, given what we already understand, but those that are "greatly at variance with preconceived ideas", Peirce invokes

16 (Rescher 1978, 69, n105, n108), (Kronz and McLaughlin 2005, 74). 
resistance (7.83). The pragmatic value of this suggestion is clear, since finding support for hypotheses that undermine current views could bear significant scientific fruit.

Supposing we take this initial suggestion seriously, we will begin to narrow the field of viable hypotheses by first determining which hypotheses we can test very cheaply. Some of these will be refuted and others will be supported by the ensuing evidence. As the testing process continues, the urgency of supported hypotheses grows, since the more support amassed for a hypothesis, the more confidence scientists will have in it, and thus the more resources they will be willing to commit to it. During the testing process, though, the question of which hypotheses deserve priority is not the only relevant question. For any sufficiently general hypothesis, there will be a number of experimental results that might be tested for. The next section addresses other of Peirce's suggestions, specifically about how to choose among the particular tests that might be performed.

\section{Determining which Experimental Results to Test for}

Peirce requires that any hypothesis, in order to count as scientific, must conform with the pragmatic maxim, the distinguishing feature of which is its implication that the meaning of any hypothesis consists entirely in its practical consequences. The question with which we are concerned here is which of those practical consequences is most economical to pursue. That is, we want to determine which empirical tests are likely to yield the best information for the costs. Kronz \& McLaughlin (2005) presents a formal expression of Peirce's recommendations for how to determine which empirical tests to perform. The recommendation is founded on Peirce's claim that we should "begin with 
that positive prediction . . . which seems least likely to be verified” (7.206). ${ }^{17}$ Kronz and McLaughlin argue that a particular way of understanding Peirce's pragmatic maxim helps us to see what should ground our probabilistic determination of the likelihood of a prediction's being verified. The upshot of the argument is that determining which of a hypothesis' predictions is least likely to be verified requires having in hand an alternative hypothesis, according to which the probabilistic assessment is to be made. It is worth taking some time to go through their argument here, since the recommendation they articulate serves to support my interpretation of Peirce's views on economy of research as instances of the general recommendation to pursue resistance.

Kronz and McLaughlin show that by the 'least likely to be verified' prediction, Peirce means that prediction that "appear[s] otherwise least likely to be true" (7.89). Understanding what would allow us to assess the likelihood of truth, here, requires understanding what Peirce means by 'otherwise'. Kronz and McLaughlin consider three possible senses, arguing in favor of the last of the three. First, 'otherwise' could mean "upon regarding the hypothesis as false" $(2005,76)$. Second, it could mean "upon omitting consideration of (i.e., upon conceptually setting aside) the hypothesis in question” (2005, 76). Third, it could mean assuming a contrary, competing hypothesis (2005, 77). Kronz and McLaughlin argue that only the third sense of 'otherwise' provides a suitable basis

\footnotetext{
17 Peirce writes that "it will be a saving of expense, to begin with that positive prediction from the hypothesis which seems least likely to be verified." While this sentence, as is, suggests that it is the hypothesis "least likely to be verified" with which one should begin, the rest of the paragraph makes clear that Peirce means the prediction, not the hypothesis. The full paragraph, without elision, follows:

Experiment is very expensive business, in money, in time, and in thought; so that it will be a saving of expense, to begin with that positive prediction from the hypothesis which seems least likely to be verified. For a single experiment may absolutely refute the most valuable of hypotheses, while a hypothesis must be a trifling one indeed if a single experiment could establish it. When, however, we find that prediction after prediction, notwithstanding a preference for putting the most unlikely ones to the test, is verified by experiment, whether without modification or with a merely quantitative modification, we begin to accord to the hypothesis a standing among scientific results. (7.206)
} 
upon which to make probabilistic assessments, provided that the hypothesis in question is suitably broad. An example will help to illustrate the point.

Consider the hypothesis that magnesium assists in muscle repair. From this, we might derive a prediction about the presence of magnesium in an animal's diet being positively correlated with muscle repair. The likelihood that this prediction is true, given the denial of the hypothesis, is impossible to assess. Given the hypothesis' denial, that it is not the case that magnesium assists in muscle repair, nothing in particular follows about how the presence of magnesium in an animal's diet should correlate with muscle repair. If, instead, we simply disregard the hypothesis, we have no grounds upon which to assess the likelihood of the prediction. If we consider some alternative hypothesis, however, for instance that magnesium plays no role in muscle repair, then we have some basis upon which to judge whether or not the prediction seems likely.

Kronz and McLaughlin argue that we should understand Peirce as recommending that scientists begin with those predictions of the hypothesis in question "that appear least likely to be true on the assumption of some competing, contrary hypothesis-the one that would be superseded if [the hypothesis in question] were confirmed” $(2005,77)$. Not only does this recommendation prove practically feasible, it is founded, Kronz and McLaughlin argue, on Peirce's pragmatic maxim. They point to a relatively late formulation of the maxim where Peirce highlights concerns not merely about hypotheses on their own, but about how they compare with other, competing hypotheses. There Peirce construes the pragmatic maxim as a measure of significant difference between conceptions, and thereby suggests that the significance of a hypothesis is best elucidated by comparison with other 
hypotheses. ${ }^{18}$ If the hypotheses have precisely the same practical consequences, then they are really the same hypothesis. If the practical consequences differ, then the hypotheses differ.

Taking Kronz and McLaughlin’s understanding of Peirce’s recommendation, then, we should begin by determining which predictions of a hypothesis have the lowest probability, given a suitable, contrary hypothesis. Once we have the least likely predictions in hand, we use other economic factors to determine whether to perform the tests. If the least likely prediction is economically prohibitive, then we look for the least likely among the remaining predictions and assess the economic feasibility of testing for it. Not only does this characterization give us practical guidance for how to gather evidence, it also accommodates a wide range of context-sensitive issues. Since the economic feasibility of performing any particular test-including political, professional, social, and personal factors in addition to concerns about equipment, funding, human power, and time-can vary quite a lot dependent on context, so may the recommendations about which tests to perform. In addition, as Kronz and McLaughlin point out, even though their analysis of Peirce's recommendation is more or less confined to the case of one hypothesis under consideration, the recommendation can be generalized to accommodate any number of hypotheses that might populate the field.

\section{Pursuing Paths of Resistance}

While the foregoing recommendations are fairly specific to research contexts and are clearly intended to accommodate the constraints that such contexts impose, there are

\footnotetext{
18 The significant passage referred to in (Kronz and McLaughlin 2005) appears at 5.196. Others, both before and after Peirce, have made similar suggestions. Paul Feyerabend argues that consideration of contrary hypotheses is necessary for understanding a hypothesis (Feyerabend 1981). John Stuart Mill made a similar suggestion in On Liberty.
} 
ways in which Peirce's general epistemological commitments are at work in these specific recommendations. In the first half of this paper, I argued that Peirce's theory of inquiry is best understood as dictating that we inquire in ways that leave open the path to future inquiry. For a method to count, on Peirce's view, as a method of inquiry it must accomplish the goal of inquiry, and so end in settling (to some degree) our beliefs about the matter at hand. In order to count as legitimate methods of inquiry, however, they must accomplish that end in a way that does not presume that the beliefs upon which we have settled are the final word on the matter. If we follow Peirce in this, we require of ourselves a constant striving, believing just what we believe, but never resting content with it. This is the attitude of the consummate scientist, accepting the best of the theories available, but never dogmatically, and always on alert for the shortcomings of those views and the possibility that other, better theories may be on the horizon.

Since science, broadly construed, serves as a model of inquiry for Peirce, we should not be surprised that the model scientist is also a model Peircean inquirer. What might be surprising, however, is the way in which realism asserts itself in Peirce's views about science and inquiry. Peirce's clear (later) commitments to realism seem prima facie at odds with his representationism, based on his claim that all thought is in signs. These two commitments are more clearly coherent, however, when one notes the roles that Peirce assigns reality in his system, especially his claim that reality manifests primarily as opposition. This claim, coupled with Peirce's conviction that truth takes reality as its object, leads to the view that inquiry is best when it maximizes opposition. The more one seeks out sources of resistance to one's beliefs, the more one sets those beliefs up for contact with reality. 
There are at least three ways that resistance is involved in the foregoing treatment of Peirce's recommendations for gathering evidence: in the preference for experiments that (economically) test hypotheses "greatly at variance" with current beliefs, in requiring consideration of contrary hypotheses for determining the least likely predictions, and in preferring those least likely predictions in the first place. While the optimal path of scientific inquiry would be the path of greatest resistance, limited resources thwart our pursuit of that path. Peirce's recommendations, though, can be understood as allowing us to nevertheless pursue paths of resistance, and indeed of contriving ways to maximize resistance within the practical constraints that must govern our inquiries.

\section{REFERENCES}

Achinstein, Peter. The Book of Evidence. Oxford: Oxford University Press, 2001.

Feyerabend, Paul K. Problems of Empiricism. Vol. 2. Cambridge: Cambridge University Press, 1981.

Glymour, Clark. Theory and Evidence. Princeton: Princeton University Press, 1980.

Hookway, Christopher J. Truth, Rationality, and Pragmatism: Themes from Peirce. Oxford: Clarendon Press, 2000.

Horwich, Paul. Probability and Evidence. Cambridge: Cambridge University Press, 1982.

Kronz, Frederick, and Amy McLaughlin. "The Complementary Roles of Chance and Lawlike Elements in Peirce's Evolutionary Cosmology." In Between Choice and Chance: Interdisciplinary Perspectives on Determinism, edited by Harald Atmanspacher and Robert Bishop, 189-207. Thorverton: Imprint Academic, 2002.

Kronz, Frederick, and Amy McLaughlin. "The Fast Track to Confirmation: Achinstein and Peirce on Evidence." In Scientific Evidence: Philosophical Theories and Applications, edited by Peter Achinstein, 69-84. Baltimore: Johns Hopkins University Press, 2005.

Levi, Isaac. The Fixation of Belief and Its Undoing. Cambridge: Cambridge University Press, 1991.

Mayo, Deborah G. Error and the Growth of Experimenal Knowledge. Chicago: University of Chicago Press, 1996.

Misak, Cheryl J. Truth and the End of Inquiry: A Peircean Account of Truth. Oxford: Clarendon Press, 1991. 
Olshewsky, Thomas. "Realism and Antifoundationalism." In Living Doubt: Essays Concerning the Epistemology of Charles Sanders Peirce, edited by Guy Debrock and Menno Hulswit, 25-32. Dordrecht: Kluwer Academic, 1994.

Peirce, Charles S. "The Collected Papers of Charles Sanders Peirce." Vols. VII-VIII. Edited by Arthur W. Burks. Cambridge, MA: Harvard University Press, 1958.

—. "The Collected Papers of Charles Sanders Peirce." Vols. I-VI. Edited by Charles Hartshorne and Paul Weiss. Cambridge, MA: Harvard University Press, 1931-1935.

Rescher, Nicholas. Peirce's Philosophy of Science. Notre Dame: University of Notre Dame Press, 1978.

Scheffler, Israel. Four Pragmatists: A Critical Introduction to Peirce, James, Mead and Dewey. New York: Humanities Press, 1974.

Short, T. L. "Peirce on the Aim of Inquiry: Another Reading of "Fixation"." Transactions of the Charles S. Peirce Society 35, no. 1 (2000): 1-23.

Skagestad, Peter. The Road of Inquiry: Charles Peirce's Pragmatic Realism. New York: Columbia University Press, 1981. 